\title{
The Vulnerability of Syrian Immigrant Pediatric Trauma Patients
}

\author{
(1) Demet Acar, (1) Mustafa Gülpembe, (1) Emin Fatih Vișneci
}

Clinic of Emergency, Konya Training and Research Hospital, Konya, Turkey

\begin{abstract}
Aim: Worldwide, 22.5 million refugees, half of them children, is a major humanity problem. Refugee children are among the most vulnerable in the world. Recently, we observed an increase in pediatric trauma cases of Syrian immigrant in our hospital. To determine the clinical characteristics of Syrian immigrant children admitted to the emergency department (ED) with trauma with respect to their frequency, socio-demographic characteristics such as living conditions, education of family, not to go to kinder-garden and corresponding high-risk injury.

Materials and Methods: This is a retrospective observational study. All records for children aged between 0-17 years were retrospectively evaluated and only patients admitted to the ED with trauma were included in the study. The data of interest investigated from patient records were age, sex, location, and timing of injury occurrence, as well as the family and education data of parents. The mechanisms of injuries were recorded as blunt or penetrating.

Results: Totally 200 children with a mean age of $8.29 \pm 4.85$ years (range: $1-17$ years) were included in the study. Falloffs were the most common cause in all age groups. Head injuries were more common compared with the extremities (82 head traumas compared with 60 upper and 32 lower extremity traumas). On the other hand, upper extremity fractures or dislocations were more common compared with the lower extremities (21 vs 3 cases). Interestingly, in this study, among 200 children included, 51 (25.5\%) were Syrian immigrants. The mean age of Syrian immigrants was younger than that of Turkish children $(p=0.002)$.

Conclusion: In that study, we have determined approximately one-quarter of the children with trauma are Syrian immigrants. Children between the ages of 1-3 years and 6-9 years, and boys were at a higher risk. Syrian immigrants cannot deal with their children enough because of living difficulties for them in Turkey. The living and educational conditions of the Syrian immigrant children who escaped from the war and took refuge should be made better and the sensitivity of the families should be increased. Kinder-garden education highly protects children from house accident so it is necessary especially for Syrian immigrant children.
\end{abstract}

Keywords: Syrian immigrant, pediatric trauma, emergency department, falls

\section{Introduction}

Trauma is the leading cause of disability and mortality among children admitted to the emergency departments (EDs). Unfortunately, in developed countries, trauma is accounting for approximately $1 / 3$ of all deaths in children $(1,2)$. Prompt diagnosis and treatment in ED is warranted for accomplished outcomes; but defining risk factors is also essential to prevent the undesirable outcomes of trauma among children.
The purpose of this study was to determine the clinical characteristics of Syrian immigrant children admitted to the ED with trauma with respect to their frequency, socio-demographic characteristics such as living conditions, education of family, not to going to go to kinder-garden and corresponding high-risk injury.

\section{Materials and Methods}

All records for children aged between 0-17 years who were admitted to the Konya Training and Research Hospital, Emergency 
Department, Konya, Turkey between May 2014 and May 2015 were retrospectively evaluated. Only patients admitted to the emergency department with trauma were included in the study. The study was approved by the local ethics committee.

The data of interest investigated from patient records were age, sex, location and timing of injury occurrence, as well as the family and education data of parents. The mechanisms of injuries were recorded as blunt or penetrating. Due to the very common nature, blunt injuries were also subdivided as motor vehicle related and non-motor vehicle related (bicycle, fall offs, sports-related, animal-related, and struck by person or object).

\section{Statistical Analysis}

Statistical analyses were performed using SPSS software (version 21.0, Chicago, IL, USA). Descriptive statistics are used and the data is expressed as numbers and percentages. A $p$ value $<0.05$ was deemed statistically significant.

\section{Results}

Totally 200 children with a mean age of $8.29 \pm 4.85$ years (range: 1-17 years) were included in the study. Among those 200 children 143 (71.5\%) were boys and 57 (28.5\%) were girls. The boys/girls ratio was 2.5 . When the patients were sub grouped according to their ages; 63 (31.5\%) were in 0-5 years of age group; 64 (32\%) were between 6-10 years of age; 73 (30.5\%) were older than 10 years of age. Maximum number of patients were at 1 year of age $(\mathrm{n}=19,9.5 \%)$ group; followed by 16 cases in 3 years and 16 cases in 8 years of age and then 2 and 6 years of ages. In Figure 1 the distribution of different ages are shown.

The mechanisms of trauma are summarized in Table 1 and the falls (68\%) were the most common cause in all age groups.

Table 1. Mechanisms of traumas in different age groups

\begin{tabular}{llll}
\hline & $\begin{array}{l}\mathbf{0 - 5} \text { years } \\
(\mathbf{n = 6 3 )}\end{array}$ & $\begin{array}{l}\mathbf{6}-\mathbf{1 0} \text { years } \\
(\mathbf{n = 6 4 )}\end{array}$ & $\begin{array}{l}\mathbf{2 1 1} \text { years } \\
(\mathbf{n = 7 3})\end{array}$ \\
\hline Penetrating injury & 1 & 4 & 4 \\
\hline Blunt injuris & & 4 & 2 \\
\hline Motor vehicle related & 2 & & \\
\hline Non-motor vehicle related & & 3 & 4 \\
\hline Bicycle & 2 & & \\
\hline Falls & & 11 & 13 \\
\hline off building & 11 & 23 & 27 \\
\hline off playground equipment & 34 & 6 & 6 \\
\hline off tree & 0 & 2 & 0 \\
\hline others (bed, or armchair) & 3 & 4 & 10 \\
\hline Sports related & 2 & 5 & 3 \\
\hline Animal related & 2 & 2 & 4 \\
\hline Shattered & 6 & & \\
\hline
\end{tabular}

Penetrating or sports related injuries were more common in older ages while falls from playground equipment were more commonly reported in younger ages, as expected.

When the seasons of traumas were evaluated; 67 (33.5\%) were in spring, 47 (23.5\%) were in summer, 7 (3.5\%) were in autumn, and 79 (39.5\%) were in winter. Interestingly, accidents in autumn were reported very rarely compared with the other seasons.

The educational level and working history of parents were also evaluated. The educational levels of mothers were as follows: 158 mothers were graduated from mid-school: while 24 were from high school: and 18 were graduated from university. On the other hand, 136 fathers were graduated from mid-school: while 35 were from high school: and 29 were graduated from university. A great proportion of mothers $(n=169,84.5 \%)$ were housewives. The other jobs reported among mothers were nurse $(n=4)$, teacher $(n=12)$, tailor $(n=5)$, employee $(n=4)$, worker $(n=3)$, architect $(n=2)$ and $\operatorname{cook}(n=1)$. On the other hand among fathers, tradesmen $(n=55)$, workers $(n=54)$, employees $(n=39)$, drivers $(n=19)$, teachers $(n=13)$, doctors $(n=7)$, farmers $(n=6)$, policemen $(n=4)$ and soldiers $(n=3)$ were present. Interestingly, only $31(15.5 \%)$ of the children had had the kindergarten education. Remaining 169 children did not get the kindergarten education.

The numbers of children living in the same house are summarized in Figure 2 and 2 or 3 children were the most common ones. On the other hand, the numbers of people living in the same house are shown in Figure 3. Eighty-one of the included families were owners of their houses while remaining 119 were tenant. Smoking history was present in 13 mothers and 130 fathers. Drinking habit was not reported in any parents.

Imaging techniques were required in many of the cases to define the exact pathology. Acute pathology was not present in physical examination and imaging techniques were not required in 35 cases. In remaining 165 cases;

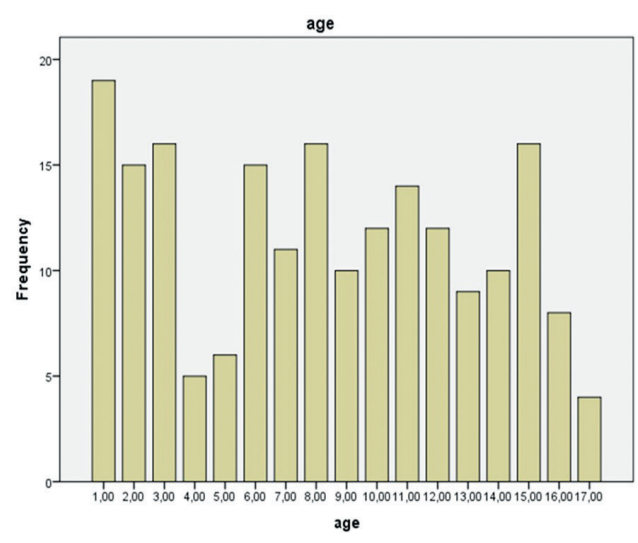

Figure 1. The distribution of different ages 


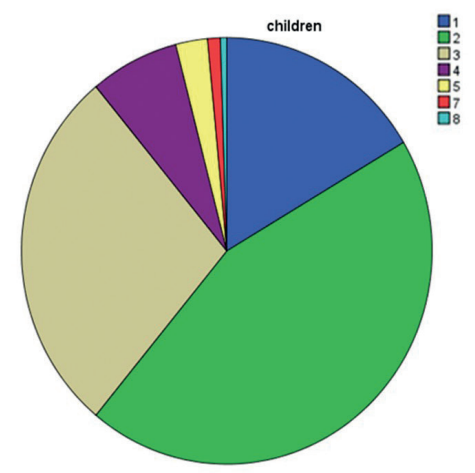

Figure 2. The Numbers of children living in the same house are summarized

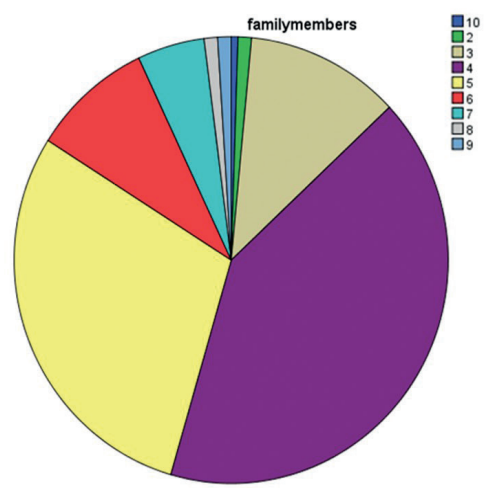

Figure 3. The Numbers of people living in the same house are shown. Purple area is more than 6 people without children

Table 2. Comparison of Syrian emigrants with Turkish children

\begin{tabular}{llll}
\hline & $\begin{array}{l}\text { Syrian } \\
\text { emigrants } \\
(\mathbf{n}=51)\end{array}$ & $\begin{array}{l}\text { Turkish } \\
\text { children } \\
(\mathbf{n = 1 4 9 )}\end{array}$ & $\mathbf{p}$ \\
\hline Age (years) & $6.47 \pm 4.78$ & $8.93 \pm 4.72$ & 0.002 \\
\hline Gender (female, \%) & $12(23.5 \%)$ & $45(30.2 \%)$ & 0.47 \\
\hline Kindergarten education & $7(13.7 \%)$ & $23(15.4 \%)$ & 0.70 \\
\hline Children living at same house & $4.45 \pm 1.45$ & $2.45 \pm 1.14$ & 0.01 \\
\hline Falls as the trauma cause & $37(72.5 \%)$ & $99(66.4 \%)$ & 0.29 \\
\hline Head injury & $23(45.1 \%)$ & $59(39.6 \%)$ & 0.43 \\
\hline
\end{tabular}

- Lower extremity radiographs were required in 32 cases; 29 were normal; foreign material (needle) on left foot was determined in 1 case, fracture on metatarsals was determined in 2 cases;

- Upper extremity radiographs were required in 60 cases; 39 were normal, there was a fracture on humerus distal end in 1 case, fracture in radius distal in 9 cases, dislocation was present on right elbow in 1 case, fracture on scaphoid was present in 1 case, fracture on left elbow in 1 case, metacarpal or phalangeal fractures in 6 cases, fracture on humerus in 2 cases;
- Fracture on pelvis was determined on X-ray in 1 case, pelvis $\mathrm{X}$-ray was normal in 2 cases,

- Abdominal ultrasound was required in 3 cases and all of them were normal,

- Hemorrhage on parotid gland was determined by ultrasound in 1 case,

- Brain computed tomography (CT) was required in 59 cases; 56 were normal, in 2 cases linear fracture was determined in frontal bone, and nasal fracture was present in 1 case;

- Cervical and thoracic CT was required in 1 case and it was normal;

- Abdominal CT was required in 2 cases; 2 were normal;

- Fracture was present in clavicle in 3 cases determined by X-ray,

- Maxillo-facial CT was required and normal in 1 case,

- Hemothorax or pneumothorax was determined in 2 cases with X-ray.

Head injuries were more common compared with the extremities (82 head traumas compared with 60 upper and 32 lower extremity traumas). On the other hand, upper extremity fractures or dislocations were more common compared with the lower extremities (21 vs 3 cases).

Interestingly, in this study, among 200 children included, 51 (25.5\%) were Syrian immigrants. The comparison of Syrian immigrants with Turkish children is summarized in Table 2. The mean age of Syrian immigrants was younger than that of Turkish children $(p=0.002)$ and the number of children living at the same house was statistically significantly higher in Syrian group $(p=0.001)$.

Our study is the first study that aimed to draw attentions to the Syrian immigrant children who exposed to house accidents because of the living conditions while escaping from the war.

\section{Discussion}

In this study, we have evaluated the children admitted to the emergency department with trauma and the results are off importance for public health in terms of primary and secondary preventions. We have determined that; traumas were more common among children at the ages of 1-3 years and 6-9 years; a great proportion of mothers were housewives; while boys and the children who did not get the kindergarten education were under higher risk. The educational level of parents of trauma patients was not high but interestingly the families were not very crowded in many families. The most common types of traumas were falls in all age groups and upper extremities were affected 
more commonly compared with the lower extremities. On the other hand, interestingly, among 200 children, 25.5\% were Syrian immigrants. The mean age of Syrian immigrants was younger than that of Turkish children. To the best of our knowledge, this is the first study reporting the condition of Syrian immigrants in Turkey concerning the pediatric trauma cases.

Head injuries were more common compared with the other parts of the body in our study. But fortunately, the majority of patients with head trauma had a minor injury that required no specific therapy, with normal findings in imaging techniques. Kim et al. (3) reported the epidemiological data of traumatic head injury among Korean children and reported that the average age of the subjects was $5.6 \pm 4.9$ years old, and $55.5 \%$ of them were $0-4$ years old with a male-to-female ratio of 2.3 to 1 . They reported the most common type of injury as collision. In our study; the male-to-female ratio was approximately equal to that ratio in all trauma patients but the mean age of the participants was higher (3). Alyafei et al. (4) aimed to describe the epidemiology and outcome of the traumatic injuries among children in Qatar and reported that the mean age of the trauma patients was 9.6 45.9 years and $83 \%$ of pediatric admissions due to trauma were male. They defined the most common type of injuries as for 0-4 years, motor vehicle or non-motor vehicle related injuries for patients older than 5 years of age (4). In a recent review of Brussoni et al. (5) it was emphasized that societal and familial gender role expectations shape boys' and girls' behaviors and parents are more likely to encourage boys to engage in risk taking behaviors. They also defined that gendered aspects of parenting practices have been associated with greater exploratory and less restrictive behaviors among boys than among girls, which may be a reason for such a great distribution difference between genders among trauma patients (5).

The growth plates, stronger periosteum, and dynamic state of growth makes the orthopedic injuries in children unique compared to those of adults (6). Upper extremities were more vulnerable to the trauma and the injuries in effected part of the body reported after trauma were also more common in upper extremities. In another study from our country, investigating the characteristics of pediatric patients exposed to road traffic accidents; the most commonly effected body parts was reported as head and neck similar with our study but in that study lower extremities were more effected than the upper ones (7).

We have determined that most common cause of trauma was the falls. Similarly, Snyder at al. (8) retrospectively studied on 5547 pediatric patients and reported the most common mechanisms of injury as falls (39\%). Motor vehicle related, sports or animal related traumas were also very low compared with falls.
With short scan time, high quality of images, and availability, computed tomography is the imaging modality of choice for the management of major traumas in many centers $(9,10)$. However its high cost and ionizing radiation used on CT that is potentially harmful especially for children are the main handicaps of CT (11). Recently, Muhm et al. (12) reported that; among 71 children admitted to the emergency department due to a trauma; $67.6 \%$ received a cranial scan and only one third of the children had had relevant trauma related findings in the CT scan. In our study CT scan was obtained in 63 (31.5\%) cases and revealed pathology in only 3 of them. However, when patients with head trauma are evaluated, separately, CT scan was obtained in 59 (71.9\%) of 82 head trauma patients. This high ratio may be associated with the small age of children since the history or physical examination may not be satisfactory for the emergency department clinicians. Recently, Glass et al. (13) reported that $53 \%$ of children with sports related head injury received CT in ED and only $4 \%$ had a traumatic brain injury on $\mathrm{CT}$ in a multicenter study. In order to reduce radiation exposure but preserve the advantages of $\mathrm{CT}$, clinicians should take the child's clinical findings more into account before taking a CT scan.

To the best of our knowledge, this is the first and only study reporting the condition of Syrian immigrants in Turkey concerning the pediatric trauma cases. The mean age of immigrants was younger than that of Turkish children. But there was not any statistically significant difference between immigrants and Turkish children regarding the gender, kindergarten education history, trauma cause or presence of head injury. Since the number of children living at the same house was significantly higher in immigrant group, it can be suggested that, young immigrant children cannot protect themselves in crowded houses.

This is a retrospective, descriptive study and the low number of study participants is the main limitation of this study. The other limitation of this study is the lack of data about the outcomes of patients, since outcomes may be of important to define the priority among patients admitted to the ED.

\section{Conclusion}

In conclusion, we have determined that the educational level of parents and children, in the meaning of kindergarten education, was not very high among trauma patients younger than 17 years of age. Children between the ages of 1-3 years and 6-9 years, and boys were at a higher risk. Though the most common side was the head, upper extremities were affected more commonly than the lower extremities. Among 200 children, 25.5\% were Syrian immigrants and the mean age of Syrian immigrants was younger than that of Turkish children. Syrian immigrants can not to deal 
with their children enough because of living difficulties for them in Turkey. The living and educational conditions of the Syrian immigrant children who escaped from the war and took refuge should be made better and the sensitivity of the families should be increased. Kinder-garden education highly protects children from house accident so it is necessary especially for Syrian immigrant children.

\section{Ethics}

Ethics Committee Approval: Konya Training and Research Hospital.

Informed Consent: Retrospective study.

Peer-review: Internally peer-reviewed.

\section{Authorship Contributions}

Concept: D.A., M.G., E.F.V., Design: D.A., M.G., E.F.V., Data Collection or Processing: D.A., M.G., E.F.V., Analysis or Interpretation: D.A., M.G., E.F.V., Literature Search: D.A., M.G., E.F.V., Writing: D.A., M.G., E.F.V.

Conflict of Interest: No conflict of interest was declared by the authors.

Financial Disclosure: The authors declared that this study received no financial support.

\section{References}

1. National Center for Injury Prevention and Control. Web-based injury statistics query and reporting system. Available at http://webappa.cdc.gov/ sasweb/ncipc/leadcaus10.html.
2. Bayreuther J, Wagener S, Woodford M, Edwards A, Lecky F, Bouamra O, et al. Pediatric trauma: injury pattern and mortality in the UK. Arch Dis Child Educ Pract Ed. 2009;94:37-41.

3. Kim HB, Kim do K, Kwak YH, Shin SD, Song KJ, Lee SC, et al. Epidemiology of traumatic head injury in Korean children. J Korean Med Sci. 2012;4:437-42.

4. Alyafei KA, Toaimah F, El Menyar A, Al Thani H, Youssef B, Mollazehi M, et al. Analysis of pediatric trauma data from a hospital based trauma registry in Qatar. Int J CritIlInInj Sci. 2015;1:21-6.

5. Brussoni M, Gibbons R, Gray C, Ishikawa T, Sandseter EB, Bienenstock A, et al. What is the Relationship between Risky Outdoor Play and Health in Children? A Systematic Review. Int J Environ Res Public Health. 2015;12:6423-54.

6. Thornton MD, Della-Giustina K, Aronson PL. Emergency department evaluation and treatment of pediatric orthopedic injuries. Emerg Med Clin North Am. 2015;33:423-49.

7. Serinken M, Ozen M. Characteristics of injuries due to traffic accidents in the pediatric age group. Ulus Travma Acil Cerrahi Derg. 2011;17:243-7.

8. Snyder CW, Muensterer OJ, Sacco F, Safford SD. Paediatric trauma on the Last Frontier: an 11-year review of injury mechanisms, high-risk injury patterns and outcomes in Alaskan children. Int J Circumpolar Health. 2014;73:25066.

9. Larson DB, Johnson LW, Schnell BM, Goske MJ, Salisbury SR, Forman HP. Rising use of $C T$ in child visits to the emergency department in the United States 1995-2008. Radiology. 2011;259:793-801.

10. Roudsari B, Moore DS, Jarvik JG. Trend in the utilization of CT for adolescents admitted to an adult level I trauma center. J Am CollRadiol. 2010;7:796-801.

11. Mueller DL, Hatab M, Al-Senan R, Cohn SM, Corneille MG, Dent DL, et al. Pediatric radiation exposure during the initial evaluation for blunt trauma. J Trauma. 2011;70:724-31.

12. Muhm M, Danko T, Henzler T, Luiz T, Winkler H, Ruffing T. Pediatric trauma care with computed tomography-criteria for CT scanning. Emerg Radiol. 2015;22:613-21

13. Glass T, Ruddy RM, Alpern ER, Gorelick M, Callahan J, Lee L, et al. Pediatric Emergency Care Applied Research Network (PECARN Traumatic brain injuries and computed tomography use in pediatric sports participants.). Am J Emerg Med. 2015;33:1458-64. 